\title{
A RECONSIDERATION OF THE HEARSAY RULE AND ADMISSIONS
}

\author{
JoHn S. Strahorn, JR. $\dagger$
}

One of the psychological assumptions implicit in the law of evidence is that all human testimony in its natural state is too untrustworthy to be considered by a jury unless its narration be conditioned in a manner calculated so to improve it in trustworthiness as to avoid the danger of the jury's being deceived into an erroneous verdict. ${ }^{1}$

Thus for such a purpose there are provided certain conditioning devices which, if desired by the opponent, must be applied to all testimony. These devices include oath, perjury penalty, sequestration, discovery, publicity, confrontation, and cross-examination, ${ }^{2}$ all of which purport to improve the trustworthiness of human testimony by presenting the stimulus of fear to the witness. The fear thus presented may be that of divine punishment (oath requirement), of human punishment (perjury penalty), or of the public disapproval incidental to the witness's being contradicted either by himself or by others (the remaining devices).

Another important conditioning device is that of normal testimonial narration in the presence of the immediate fact finder. This presents to the witness the stimulus of fear of the power and dignity of the tribunal and also leads to more accurate acquisition of meaning by the latter because of the advantage of the fact finder's being able to observe the demeanor and tone of voice of the witness as he narrates. It is felt that the fact finder gets

$\dagger$ A. B., I922, St. John's College ; LL. B., I925, Washington and Lee University; S. J. D., I926, Harvard University; J. S. D., I93I, Yale University; Professor of Law, University of Maryland School of Law; author of The Effect of Impossibility on Criminal Attempts (I930) 78 U. of PA. L. Rev. 962; Criminology and the Law of Guilt (I936) 84 U. of PA. L. REv. $49 \mathrm{r}, 600$, and other articles in legal periodicals.

r. Other types of rules also seek to avoid the danger of an erroneous jury verdict being induced by untrustworthy evidence. Thus certain rules of objective trustworthiness (leading questions, opinion rule, and the preferences for documentary originals, attesting witnesses and verbal completeness) proceed on the basis that certain evidence, no matter who the witness, is either worse or better than normal, properly conditioned testimony. The rules of subjective trustworthiness concern themselves with the effect which the personality of the witness will have on the trustworthiness of his testimony. Another important group seeks to avoid the danger of erroneous jury verdicts being caused by the confusing effect upon the jurors of evidence which is intrinsically trustworthy. Still another group seeks to serve policies entirely extrinsic to that of securing valid jury verdicts by privileging or otherwise regulating the production of evidence. The present writer, in an earlier article, has attempted to outline all the rules of evidence in terms of their policies. See Strahorn, Extra-Legal Materials and the Law of Evidence (1934) 29 ILL. L. REV. 300.

2. The grouping of cross-examination with numerous others of the conditioning devices, and without discussion, is not meant to convey any impression of its unimportance. Rather, the beneficent influence of cross-examination as leading to trustworthiness will be discussed at later and more appropriate places in this article. In addition to inducing trustworthiness by subjecting the witness to the fear of self-contradiction, cross-examination reaches the same end by bringing out more complete detail of the witness's testimonial knowledge and by exposing defects in his perception, recollection, and narration. 
a more accurate idea of the facts from the witness when he hears the narration than when he is merely informed concerning the previously narrated testimony. ${ }^{3}$

Then, too, narration in the normal manner affords certain other devices which are also available to improve the trustworthiness of human testimony. The process of refreshing recollection, the use of maps, diagrams, photographs, and interpreters, and of other devices concerned with the perception, recollection, and narration of the witness all tend to remove from human testimony some of its native lack of trustworthiness. So it is that the formal method of narration, i. e., response to questions prepared by trained counsel, tends to make the narration more meaningful and relevant in the pending case and so the jury acquires a more accurate meaning. Even an uninterrupted narrative formally given in testimony would be superior to a casual utterance made neither under the conditioning devices nor designedly to aid a fact finder.

The basic psychological assumption that all human testimony is untrustworthy is probably a valid one. Human testimony is generally less trustworthy as a device for the fact finder's acquiring meaning concerning the thing in dispute than would be an inspection of the thing itself. Real evidence is obviously better than testimonial evidence. The law's suspicion of testimony is tied up with the requirements of the basic elements of testimonial evidence, viz., perception, recollection, and narration. Not all human utterances are permitted to be used as evidence, but only those which represent the recollected and perceived knowledge of the witness and which are narrated in the approved fashion. If the witness did not perceive the facts, or having done so, if he does not remember them, or, even if he did both, unless he narrates his recollected knowledge in a manner approved by the law, his statements may not be considered by a jury in order to persuade them of the facts.

The assumed lack of trustworthiness of human testimony is based upon the normal possibility of defects in the perception, recollection, and narration processes of the individual witness. The witness may not have perceived accurately. Or he may have forgotten so much of what he did perceive as to render inaccurate the meaning acquired by the jury about that which he does remember. Further, even assuming accurate perception and recollection, language difficulties or inept choice of phraseology may make the narra-

3. Dean Wigmore chooses to subsume narration in the presence of the fact finder under "confrontation", thus making that concept include confrontation by the opposite party and confrontation of the witness by the fact finder. See 3 Wigmore, Evidence (2d ed. I923) \$ I395. For that matter, why not stretch "confrontation" to include confrontation by the public, thus making publicity of narration also unnecessary as an additional concept? The present writer thinks it better to separate the three concepts of confrontation by the opposite party, publicity of narration, and narration in the presence of the fact finder, each of which makes its own peculiar contributions to the cause of trustworthiness. For a treatment of the two possible meanings of confrontation as Dean Wigmore conceives it, see Bohn, Prior Inconsistent Statements as Substantive Evidence (1936) 2I ST. LouIs L. REv. I22, I32. 
tion inaccurate. Finally, the witness may intentionally render an inaccurate meaning, i. e., he may lie. The probability of one or more of these defects appearing in the average human testimony about the usual human experiences has resulted in rules assuming that all testimony is subject to such faults. So it is that we have the requirement of the various devices just mentioned which attempt to rectify the errors in human testimony.

The rule excluding hearsay forbids the use of extra-judicial statements for the purpose of proving the truth of their content. It is essentially an application of the requirements of the conditioning devices and of the testimonial elements of perception, recollection, and narration. When we consider hearsay as the narration of the previous speaker's recollected knowledge, we see that it was not made under the beneficent influence of the conditioning devices calculated to make human testimony sufficiently accurate to be heard by a jury. When we view it from the angle of the witness on the stand who is subject to those devices, we see that he does not possess recollected perception of the fact sought to be narrated, viz., the content of the utterance.

Thus the hearsay rule generally has no particular psychological problem other than those implicit in the requirements of the conditioning devices and of perception, recollection, and narration, although, as we shall see, the hearsay exceptions do have psychological implications in their own right. There is, however, a factor about hearsay which further shows its untrustworthiness. To allow hearsay evidence generally would be to run twice the normal risk of defect in the testimonial process. Not only would there be the primary risk of defective perception, recollection, and narration as to the fact in question on the part of the one who uttered the original statement, but there would be a similar secondary risk in the perception, recollection, and narration of the person who heard or saw the fact of the utterance of the extra-judicial statement and who is offered to reproduce it in court. While such a person's narration would be subject to the conditioning devices, yet these merely aid, and do not guarantee the trustworthiness of his testimony.

Thus it is that an important consideration in evaluating departures from the hearsay rule is whether the extra-judicial statement to be permitted has less than the normal danger of error in its being reproduced in the court room. This is incidentally important under the heading of "hearsay rule partially satisfied" and is of more significance in connection with the genuine hearsay exceptions. To the extent to which the extra-judicial utterance is in writing, or is perceived by a trained observer, or is of a sort itself likely to be well perceived, briefly or accurately remembered and simply narrated, the secondary danger of untrustworthiness in its reproduction is avoided and more reason is present than otherwise for allowing the statement to be proven despite the hearsay rule. 
The hearsay rule is more famous for what it permits than for what it forbids. In such a vein the ensuing discussion will be divided in terms of what extra-judicial utterances are permitted to be proven despite the rule. These fall into three general headings: (I) hearsay rule inapplicable, wherein extra-judicial utterances are used, but not testimonially, and so do not raise any problem of trustworthiness; (2) hearsay rule partially satisfied, which comprehends extra-judicial utterances offered testimonially but acceptable because actually made or reproduced under the influence of some of the conditioning devices; and (3) the genuine hearsay exceptions, which permit entirely unconditioned extra-judicial utterances to be offered testimonially because for good reasons the conditioning devices are dispensed with.

Hearsay rule inapplicable includes those human utterances not made under the influence of the conditioning devices which are offered to the fact finder not as human testimony or narration of perceived and recollected experience, but rather because the fact of their being uttered, regardless of the trustworthiness of the utterance, has some relevant bearing on the case. When they are permitted to be used, it is because the utterances are offered as conduct and not as narration. In the second and third groups they are used as narration only.

Hearsay rule partially satisfied covers the use of certain extra-judicial statements as narration of perceived and recollected facts. This is permitted either because the narration was made under the then present influence of all possible of the conditioning devices so that, for present purposes, the only one lacking is narration in the presence of the immediate fact finder, or because the conditioning devices are applied to the narrator subsequently to the narration and concerning the accuracy of his prior narration.

The gemine hearsay exceptions permit the use as narration and for testimonial purposes of various extra-judicial statements not made under the influence of any of the conditioning devices but necessary to be used in the case. The admissibility of such statements may be justified for one or the other of two reasons concerned with the trustworthiness of the narration, i. e., either because there is present at the time of the utterance some stimulus of equal efficacy with the conditioning devices in improving trustworthiness, or because the intrinsic nature of the particular narration is such that it is exceptionally trustworthy in its own right and so much so as to render unnecessary those devices set up to improve testimony of but normal trustworthiness.

It is planned to treat of the hearsay rule in terms of the above three headings and their appropriate sub-topics. In the course of the discussion the writer plans to develop the following points: (I) whether it is the lack of cross-examination alone, or the lack of all the conditioning devices, which 
makes hearsay objectionable; (2) whether the explanatory factor in the various hearsay exceptions is a positive "circumstantial guarantee" of trustworthiness or a negative lack of untrustworthiness in the typical evidence permitted; and (3) the place of admissions with reference to the hearsay rule. This last topic, as will be argued, belongs under "hearsay rule inapplicable," but, as discussion of it requires a basic understanding of the whole analysis of the hearsay rule, it is planned to postpone the detailed treatment of it until the latter part of the article after the hearsay rule and its departures generally have been discussed. In laying a foundation for a treatment of these several points it will be necessary for the writer to sketch an analysis of the whole hearsay problem which will unavoidably entail the reiteration of much that is extant in writings on the subject. ${ }^{\dot{4}}$

\section{Hearsay Rule InAPplicable}

Whenever it is sought to prove in court the previously made oral or written statement of any person, the obstacle of the hearsay rule presumptively presents itself. In three groups of situations, however, it is permitted to prove what someone said or wrote. The first of these, now to be treated, arises by way of logical deduction from the wording of the rule itself, and involves a type of utterance to which the rule, by definition, does not apply at all. The hearsay rule forbids the use of extra-judicial statements for the purpose of proving the truth of their content. Those statements which are offered not to prove the truth of their content, but for some other relevant purpose, do not, by definition, come within the ban of the rule.

Thus the basic distinction which the hearsay rule forces us to make between the topic of hearsay rule inapplicable and the other two headings is that between statements as conduct and statements as narration. ${ }^{5}$ Those statements the use of which in the case can be justified as the non-narrative conduct of the speaker are permitted despite the hearsay rule, since it is

4. Professor Morgan has written extensively both on the hearsay rule and on admissions and in the present article frequent reference will be made to his articles. For purposes of convenience in citation they will all be listed in this footnote so that further citation of them may be made by reference back to this footnote and to the designation of the individual articles by the Roman numerals used below: I. Morgan, Admissions as an Exception to the Hearsay Rule (I92I) 30 YALE L. J. 355; II. Morgan, A Suggested Classification of Utterances Admissible as Res Gestae (I922) 3I YALE L. J. 229; III. Morgan, The Relation Between Hearsay and Preserved Memory (I927) 40 Harv. L. REv. 712; IV. Morgan, The Rationale of Vicarions Admissions (I929) 42 HARv. L. REv. 46I; V. Morgan, Hearsay and Non-hearsay (I935) 48 HARV. L. REV. II38.

5. The converse problem of non-narrative conduct being excluded from evidence because it circumstantially amounts to narration and therefore runs afoul of the hearsay rule is presented in the case of Wright v. Tatham, $5 \mathrm{Cl}$. \& F. 670 (I838). In that case the question was the sanity of a testator. There was excluded proof of the conduct of other persons in consulting with him seriously in business matters. This was on the theory that such proof amounted to the statements of such persons that they considered the testator sane. Both the hearsay and the opinion rules were thought likely thus to be violated. For a discussion of the problem see McCormick, The Borderland of Hearsay (1930) 39 XALE L. J. 489; Morgan, supra note $4, \mathrm{~V}$. The matter of the translation of conduct into narration is also involved in the topic of implied admissions, to be treated in the concluding installment of this article, to appear in the April issue of the Review. 
inapplicable to them. Those statements which cannot be rationalized as nonnarrative conduct and which are at most only the narration of the speaker's recollected knowledge fall within the ban of the hearsay rule and are forbidden to be considered testimonially save where they come under either the principle of hearsay rule partially satisfied or one of the genuine hearsay exceptions.

The problem of hearsay rule inapplicable or of statements as conduct instead of as narration has no psychological aspect. ${ }^{6}$ Rather, the matter is a logical one of whether the utterance is usable for some other purpose than as testimonial narration. The hearsay rule exists because of the probable untrustworthiness of that which falls within its ban. If an extra-judicial utterance is of value to the case regardless of its trustworthiness, then the ban of the rule is inapplicable and the statement is admitted. Thus the essential question for allowing the use of statements under the instant principle is: can a justification be found for using it which ignores the trustworthiness of the utterance? The conditioning devices (the lack of which is the raison d'être of the hearsay rule) need only be applied to those utterances the trustworthiness of which is a problem.

A preliminary test for determining whether a statement comes under hearsay rule inapplicable is whether on its face it purports to narrate any then past and relevant event. If from its appearance it does not purport to tell any story, or any story of possible relevance in the instant case, then it is clear that the hearsay rule is inapplicable and the statement may be proven, if at all, under one of the principles presently to be discussed. If, on the other hand, the statement does have narrative content of interest in the instant case, it may nevertheless still come under the principle of hearsay rule inapplicable if it also has some significance as conduct. In such event the jury should be instructed not to consider it for its narrative effect. This is done for prior inconsistent statements ${ }^{7}$ when used to impeach, where the statement obviously does also have narrative effect and it is secretly hoped by the offering side that the jury will give it such. ${ }^{8}$ The point is that a state-

6. The rules of evidence generally involve three separable psychological problems, each integrated with one of the general types of rule. Thus, the rules which involve the policy of trustworthiness center around the psychology of the witness or of testimony. The rules seeking to avoid jury confusion are not concerned with that, but rather with the psychology of the juror or of judgment making. The rules of extrinsic policy involve neither the psychology of witnesses nor of jurors, but rather that of human beings in the assorted human relations sought to be fostered by the various rules. In connection with the psychological policies of the divers rules, see Strahorn, supra note I.

7. This is the orthodox view. Compare Dean Wigmore's theory that certain prior inconsistent statements should be considered as substantive evidence in the case. WIGMrore, $o p$. cit. supra note $3, \S$ Ior8. For an excellent treatment of Dean Wigmore's view, anent a case following it, see Bohn, supra note 3 .

8. The rule for prior inconsistent statements limits them to such as could have been testified to on the witness stand, $i$. e., requires them to concern matter relevant in the instant case, and forbids them to concern "collateral" matter. The policy of this is, of course, to avoid jury confusion by eliminating the dead weight of additional and collateral matter, and by confining 
ment may be offered in evidence if any justification or excuse can be found for using it which ignores the trustworthiness of the statement, even though there is also a possible secondary and narrative effect which may but should not be given to it. The hearsay rule applies only to statements whose sole value to the case is as narration.

The subsidiary topics found under hearsay rule inapplicable, or the use of prior utterances as conduct instead of as narration, ${ }^{9}$ are: (I) utterances as operative conduct; (2) utterances as parts of relevant conduct; (3) utterances as themselves relevant circumstantial conduct; (4) prior inconsistent statements to impeach witnesses; and (5) admissions. Of these five headings the first three cover the whole field of hearsay rule inapplicable. The fourth and fifth are species of one or more of the first three and are listed separately only because of their importance. ${ }^{10}$

\section{Utterances as operative conduct}

If the making of the utterance is the ultimate thing sought to be proven in the case, rather than a device for proving that thing, the suspicion of hearsay attaches the least. So it is that the topic of utterances as operative conduct is the one of simplest application under the hearsay rule. No question of possible testimonial or narrative use can arise when the speaking of the words determines the rights being litigated. Thus it is that such typical examples as the making of a promise, the speaking of a slander, the printing of a libel, the speaking of marriage vows are all species of extra-judicial utterances provable despite the hearsay rule because they are the operative conduct of the speaker. For them there is no possible question of the trustworthiness of the utterance and no demand that it be made in the presence of the conditioning devices. Therefore the hearsay rule is inapplicable.

\section{Utterances as parts of relevant conduct ${ }^{11}$}

Another justification for getting an extra-judicial statement into the case on the theory of its being relevant conduct and not narration is that it

the jury's attention to matters already within their purview. The effect of it is, however, to tempt the jury with statements possessing possible narrative value in the case. See Bohn, supra note 3 .

9. For an acute analysis of the difference between narration and conduct, anent the problems of hearsay generally and of specific exception to the hearsay rule, see Seligman, $A n E_{x-}$ ception to the Hearsay Rule (I913) 26 HARv. L. REv. 146. See also Morgan, supra note 4, V.

Io. For that matter, as we shall see, many statements are of value to the same case both as hearsay rule inapplicable and as admissible hearsay under some one of the genuine hearsay exceptions, or even as hearsay rule partially satisfied. One and the same statement may, in a given case, be both an admission and a declaration against interest. Former testimony may come in both as such and as an admission. A threat to murder, communicated to the defendant, may be both a genuine hearsay exception statement of mental condition and a circumstantial utterance justifying defendant's conduct. A spontaneous exclamation may also be an admission or a statement of mental condition.

II. Professor Morgan, supra note 4, II, has carefully distinguished the various types of utterances which are admissible under the res gestae. He makes a finer division of utterances 
is part of contemporaneous non-verbal conduct which is itself relevant, either as an operative fact or as circumstantial evidence. Whenever the contemporaneous non-verbal conduct of one who is speaking, writing, or handling a writing is relevant in the case, and is in need of interpretation in order for the utmost meaning concerning it to be acquired by the fact finder, the fact of the spoken or written utterance may be considered by the fact finder for that purpose. This rule for statements or declarations accompanying a relevant act requires, of course, that the statements or declarations be part of and explain an act otherwise relevant which is in need of explanation. It is not that someone is speaking while he is acting that gets the statement around the hearsay rule. It is that the act itself has independent relevance in the instant case, is in need of further explanation for the purposes of that case, and is so explained by the contemporaneous oral or written act. The important thing is that utterances which would have no status as being relevant conduct in their own right may acquire standing in the case because they forn a part of non-verbal conduct which does have such a status.

\section{Utterances as themselves relevant circumstantial conduct}

If an utterance is neither operative in the case, nor explanatory of the speaker's contemporaneous non-verbal conduct, it may still be provable despite the hearsay rule if it can stand by itself as conduct relevant to the case in a circumstantial way. We have seen that the justification for using operative utterances is the relation between the utterance and the substantive issues in the case. The justification for using utterances as parts of relevant conduct is the relation between the utterance and the contemporaneous conduct of the speaker. Here the rationale of utterances as themselves relevant

as parts of relevant conduct than does the present writer. Thus his third and fourth categories divide the usual one for declarations accompanying a relevant act into: " $(3)$ Cases in which the operative effect of non-verbal conduct depends upon verbal conduct accompanying it"; and "(4) Cases in which the operative effect of non-verbal conduct depends upon the intent which accompanies it." Furthermore, he sets up another category which seems to be on the borderline both of what is here conceived to be the declaration accompanying a relevant act and the genuine hearsay exception for spontaneous exclamations: "(6) Cases in which the utterance is contemporaneous with a non-verbal act, independently admissible, relating to that act and throwing some light on it." Professor Morgan considers utterances in this class as used for narrative purposes. With this the present writer disagrees, believing as he does that the utterances of this class, as well as those of classes (3) and (4) all belong under the single category of utterances which are parts of relevant conduct and which come in as conduct and not as narration alone. Aside from this, Professor Morgan's categories are the orthodox ones, to which the present writer holds: (I) is the equivalent of what is here called "utterances as operative conduct"; (2) equals what is here referred to as "utterances as themselves circumstantial conduct"; (5) covers the genuine hearsay exception for statements of physical and mental condition; and $(7)$ is the genuine exception for spontaneous exclamations. Professor Morgan's insistence that the utterances in class (6) are used as narrative is, of course, consistent with his thesis concerning admissions. The present writer disagrees as well with the one as with the other. He agrees, of course, with Professor Morgan and numerous others that the phrase "res gestae" should be abandoned as confusing and meaningless. Its use will be avoided in the present article. 
circumstantial conduct is the relation between the utterance and either the conduct of others than the speaker or the non-contemporaneous conduct of the speaker.

Utterances which, either because of their being made by certain persons or because of their being made under certain extrinsic circumstances, have probative force in the case regardless of their being true or false are admissible as circumstantial utterances despite the hearsay rule. The essential test is that the utterance must have some relevant value and as much if it be false as if it be true. If this be so (as for all types of hearsay rule inapplicable) no problem of trustworthiness arises, the conditioning devices are not needed, and the hearsay rule which applies only to utterances needing and lacking such conditioning is, by definition, inapplicable.

Thus a ludicrous statement by one whose sanity is in question will prove circumstantially his insanity. A dog owner's warning to a neighbor to "beware the dog" circumstantially proves the owner's knowledge of the dog's vicious nature. A mother-in-law's advice to her son to return to his wife will prove circumstantially either that she did not alienate his affections or that she lacked malice toward her daughter-in-law. The fact of the defendant's hearing a threat uttered by the victim circumstantially bears on the defendant's relevant belief of the need for exercising self-defense. That many persons commented on the dangerous condition of premises circumstantially proves that the owner thereof must have been aware of the danger. The probative force of the circumstantial utterance lies in its inconsistency with the validity of the contention of the side against which it is offered.

A statement made by or to a certain person may circumstantially prove something about the separate conduct either of the speaker or the person having knowledge of the statement, and without reference to the trustworthiness of the statement as narration. This is so even if its content can possibly have an alternative narrative effect, i. e., refer to a past event as such. The determination of what statements do have this possible non-narrative and circumstantial effect is a matter of the logic of the process of proof. If general human experience indicates that the fact of the statement's being uttered tends to prove something of interest to the instant case concerning the speaker or the possible recipient of the statement, then it is an example of a circumstantial utterance to which the hearsay rule is not applicable because it does not apply to statements offered as conduct rather than as narration.

The usability of a statement as relevant circumstantial conduct depends on the identity of the speaker, the identity of the hearer, the surrounding extrinsic circumstances, and the manner in which the litigation subsequently develops. The circumstantial value of the statement comes in by way of the state of mind of either the speaker or the hearer. The statement tends 
to prove the motive, knowledge, belief, intent, emotion, sanity, malice, or any other mental state either of the speaker or the hearer if human experience indicates that the speaking or the hearing of such a statment shows that the speaker or hearer does possess such a mental state.

\section{Prior inconsistent statements to impeach witnesses}

A species of circumstantial utterance which is sufficiently important to call for separate listing is the prior inconsistent statement of a witness, which may be offered to impeach him. The credibility of a hostile witness may be impeached, among other ways, and after complying with certain detailed rules not germane to the present discussion, by proof of his previous conduct in making a statement inconsistent with his present testimony in court.

When such a statement is admitted, the theory is that it is used without reference to its trustworthiness, and not to prove its content, but merely because the circumstance of the inconsistency between the statement in court and the statement out of court shows that the witness possesses a tendency to lie. Thus it is that the jury should scale down his statements in court. The circumstance of the inconsistency between two instances of his narrative conduct is thought to reflect the nature of his capacity for telling the truth on all occasions and on this specific one. ${ }^{12}$

\section{Admissions}

Because proper treatment requires that the whole analysis of the hearsay rule be kept in mind, admissions will not be discussed until the end of this article. Now nothing more than a brief caveat of the writer's thesis concerning them and their relation to the hearsay rule will be stated. The writer prefers the view concerning admissions which holds that they are used under the doctrine of hearsay rule inapplicable and he rejects the view that they are admissible under a genuine hearsay exception, or under any other narrative theory. It is believed that some vicarious admissions are species of utterances which are parts of relevant conduct and that others of them, and also both tacit admissions and express admissions by the party himself, are types of utterances which are themselves relevant circumstantial conduct.

12. On the other hand, prior consistent statements are usually rejected when offered to sustain the credibility of an impeached witness. This may be rationalized in several ways. First, because proof of prior consistent statements does not contribute anything to the issue of credibility, inasmuch as it merely goes further to show the inconsistency in the witness's narrative conduct, already sufficiently demonstrated by the proof of his inconsistent statements. Second, because the circumstance of consistency in narrative conduct is a weaker one than is that of inconsistency and hence has less probative force. Third, because allowing the use of consistent statements will tend to increase the dead weight of the case and thus to confuse the jury more than is compensated for by the relevance of the evidence on the collateral issue of credibility, whereas inconsistent statements are likely to be fewer in number and their greater probative force will be sufficient to outweigh the confusing effect the dead weight will have on the jury's minds. 


\section{Hearsay Rule Partialiy Satisfied}

If an extra-judicial statement which has been offered in evidence cannot possibly have its use justified as conduct and gives aid in the case only as the narration of a fact known and recollected by the declarant, then the hearsay rule applies and the utterance will be excluded unless it comes under one of the principles permitting extra-judicial utterances to be used for their narrative effect. The first one of these is the instant topic of hearsay rule partially satisfied, which permits the testimonial use of previous narrative utterances if either the narration was made under the possible presence of all the conditioning devices save the obviously impossible one of presence of the immediate fact finder (former testimony), or if the previous entirely unconditioned narration was in writing and the narrator can presently be subjected to all the conditioning devices in an inquiry concerning the former narration (past recollection recorded).

\section{Former testimony 13}

This topic involves showing to the present fact finder the fact of a person's having previously narrated his recollected knowledge in a judicial proceeding. It is hoped thereby that the present fact finder will give the testimony as much effect as if the same words were uttered in his very presence. In almost all of the instances under this principle the secondary danger of error in the reproduction of the former utterance is largely avoided because the stenographer's transcript will be available, to be used by him as a record of his past recollection of his experience in hearing the utterance. In view of the further facts that he is a trained observer and has prepared a memorandum promptly thereafter, with the aid of which he narrates, the dangers of error in his perception, recollection, and narration are minimized. ${ }^{14}$ Former testimony usable under this principle is of three sorts: (I) normal testimony taken at a former stage of the same case; (2) depositions taken designedly to be used in the pending case; (3) testimony

I3. At the present time we are speaking of the use of former reported testimony as itself testimony in the present case. Narration actually made previously in the form of testimony in court, depositions taken for court use, or testimony taken to perpetuate it may also be used, if the circumstances are appropriate, as a party opponent's admission, as a prior inconsistent statement to impeach a witness who actually testifies in an inconsistent manner at the later hearing, and to refresh or as a record of the past recollection of the former witness if he again takes the witness stand and alleges loss of recollection of the matter previously testified to. To this end, it is tactically important that the witness shall have read over (and preferably shall have initialed) a copy of the testimony at some prior time when the recollection was still fresh in his mind so that the requirements for past recollection recorded shall have been complied with.

I4. Or if the stenographer is unavailable, his transcript may be used (if local statutes permit) as an official government record, or to refresh the recollection of an ordinary witness who was present when the original testimony was given. This is particularly so for counsel in the former case who were present. Either the transcript may be used to refresh recollection or, if (as is probable) counsel read over and verified a copy of the transcript while the knowledge of what the witness said was fresh, it will be a record of past recollection recorded prepared by another but verified by the present witness. 
previously taken under appropriate procedure for preserving evidence for future use.

The common denominator of all these is that narration in the presence of the immediate fact finder is dispensed with. But in each such instance it is felt that the possible loss of trustworthiness is outweighed by the need for using such extraordinary testimony to avoid losing entirely the benefit of the narrator's knowledge. There must be a necessity for using it. These three further have in common the actual subjection of the extra-judicial narration to the more important of the remaining conditioning devices and the possible subjection of it to all of them, although certain ones are rarely, if ever, used. Thus this extra-judicial narration is made under oath, perjury penalty, and cross-examination. Sequestration, publicity, and confrontation are rarely used, although the substantial effect of sequestration can be accomplished by examining only one witness at a time; the effect of publicity is achieved by the interval elapsing between the narration and its consideration by the tribunal; and actual confrontation by the opposite party at the former narration might easily have happened. That the testimony is taken some time before it is considered accomplishes the end of discovery.

If between two stages of the same case a witness who testified at the first stage dies or otherwise becomes unavailable, his former testimony may be used at the later stage if the parties and issues remain the same. All of the conditioning devices were available at the first stage, and so using it at the second involves only the loss of the presence of the immediate fact finder. That the parties and issues remain the same indicates that there was previously a normal opportunity by the very same party to cross-examine in a manner presently relevant. Opportunity to cross-examine generally will not satisfy that one of the devices. Rather, it must be an opportunity to the same person (or to one in privity) to cross-examine with reference to the same issues. Different persons might cross-examine in a different manner and the same person differently with varying issues.

So it is when depositions are taken designedly for use in a pending case under locally applicable procedural rules. This is allowed exceptionally in all civil cases and occasionally, as in the equity practice, is the rule rather than the exception. All of the conditioning devices are applied, or their effect is accomplished by the nature of the proceeding. The opportunity is afforded to the very opponent to cross-examine in the instantly relevant manner.

Certain procedural devices, variant locally, provide for the taking of testimony against a future need for its use at the time when the witness either may be unavailable or will have forgotten what he knew. Under this procedure, as for depositions, all of the conditioning devices are either actually presented, or their effect is accomplished. The requirement of notice 
to interested parties and the indicated nature of the issues on which it is expected to use the evidence in the future insure to the future opponent a present opportunity to cross-examine in what will turn out to be a relevant manner.

\section{Past recollection recorded}

In the case of past recollection recorded, it is permitted a witness to offer in evidence a memorandum of his previously narrated recollection of his still previously acquired knowledge. Usually this record must have been prepared by the witness himself, or by another in his presence, or by another and verified by the witness while the knowledge was still fresh in his mind. The witness must also be able now to testify concerning whichever one of these circumstances justifies the use of the records. When this is done the record itself stands as the narration. As it is narration not actually made under the influence of the conditioning devices, the obstacle of the hearsay rule presumptively presents itself.

It is inappropriate to think of permitting the use of such a record as involving a genuine hearsay exception. ${ }^{15}$ There is nothing about the narration, as such, to make it so intrinsically superior as to justify dispensing entirely with the application of the conditioning devices. As the rule for past recollection applies, it extends to all types of perception, good and bad, with no limitation of time or extraordinary circumstances to insure unusual recollection, save that obviously the narration was made sooner after the event than normal narration in the courtroom. The only superiority of narration is that found in the relatively greater care with which written words are chosen than oral ones. Motivation to falsify is normal. But these items of superiority, viewed in the whole, do not make such narration as intrinsically superior as that demanded for the various genuine hearsay exceptions.

Rather than as a genuine exception, past recollection recorded must be justified as an item of hearsay rule partially satisfied by the partial application of the conditioning devices. The conditioning devices were not, to be sure, applied to the narrator at the time of his narration. But as the rule works out, they must be applied in normal manner to the process of reproducing the writing for courtroom use, and then to the very same person who either made or used the writing as the vehicle of his former narration. This makes for superiority in the process of reproduction. Rather than lose entirely the benefit of the witness's one-time relevant knowledge, the law is willing to take the slight risk of loss of trustworthiness and to permit the narration to be conditioned ex post facto and nunc pro tunc. While in the case of former testimony expediency dictates accepting testimony given

15. The present writer formerly considered past recollection recorded as involving a genuine hearsay exception. Strahorn, supra note I, at 316 . Subsequent reflection has convinced him that the view stated herein is the better one. 
under less than all of the devices, here we see that it permits narration made under none but where the narrator can subsequently be exposed to all of them concerning whatever he still does remember of the transpired event and the circumstances of his having previousily narrated his then more perfect recollection of his knowledge. In either event, the hearsay rule is partially satisfied either by the incomplete or imperfect application of all the conditioning devices. Thus testimony not itself of any necessarily intrinsic superiority is made available to the case in order not to lose the benefit of it entirely.

Normally the hearsay rule as readily applies to extra-judicial statements by one who is later a witness in the case as to those by persons who are not witnesses and who are never subjected to the conditioning devices. The rule for past recollection recorded furnishes a striking departure from this principle and, as we have seen, permits the subsequent conditioning of the narrator in the courtroom to take the place of the usually required conditioning at the time of the narration. The existence of this departure from the hearsay rule suggests the possibility of others wherein the subjection of the witness to the conditioning devices in court might make his previously unconditioned narration sufficiently trustworthy.

One such possibility is the use of prior oral statements as records of past recollection. Suppose the witness who observed the relevant fact has completely forgotten his experience by the time he is called to court, but, at a time when he did remember, had orally narrated his knowledge to another witness who himself is now available to testify concerning what was narrated to him by the first witness. Professor Morgan has thoroughly analyzed this problem in one of his articles. ${ }^{16}$ If prior written narration can be reproduced in court when the narrator is being subjected to the conditioning devices, why can not also properly reproduced prior oral narration be considered just as trustworthy? Were accuracy of reproduction of the major witness's prior narration equally sure, there would be no difference between prior written statements and prior oral statements as recorded recollection. But prior oral statements run into the danger of error in their reproduction. In the case of oral statements it is not so certain that the witness did actually say the things alleged. As the rigid rules for past recollection apply, ${ }^{17}$ there is in the case of prior written statements little danger of error as to what the witness did formerly say. What he said is proven by real evidence, i. e., the writing. But this is not true in the case of oral statements where proof of what he said depends on defective human perception, recollection,

I6. Morgan, supra note 4 , III.

17. Because it is usually required that the statement be made either by the witness, or by someone else in his presence, or by someone else and be verified by him while the knowledge is still fresh in his mind. As a result the witness is sure that he did once narrate the very words now offered. 
and narration of another's spoken words. Thus it is that, on a relative basis, it is safer to permit subsequently conditioned written statements than subsequently conditioned oral ones. Oral "records of past recollection" may be trustworthy, but they are not as trustworthy as written ones.

Another possibility in the way of allowing subsequently conditioned narration is involved in Dean Wigmore's suggestion that prior inconsistent statements should be given substantive weight in the case (if we assume that he means thereby that they should be given narrative ${ }^{18}$ and not merely circumstantial effect). Dean Wigmore apparently contends that prior inconsistent statements, when admitted by the witness, should be allowed testimonial effect because the witness is in court and subjected to crossexamination (and the other conditioning devices). The distinction is aptly taken between those prior inconsistent statements admitted by the witness and those proven extrinsically after his denial. For the former there is little danger of error in the manner of their being reproduced in the courtroom, i. e., they are reproduced by the same speaker and under circumstances so embarrassing to him as to make it likely that he did so formerly narrate. But where the witness denies making the former statement and it has to be proven extrinsically by another witness who heard it, there is then the same danger of error in the reproduction of the former statement as was discussed for oral "records of past recollection". It would also seem inappropriate to extend the principle of hearsay rule partially satisfied to prior consistent statements. If they are to be proven by the witness' own statement, there is too much danger of untrustworthiness in that he may be trying to "lift himself by his own bootstraps" to make his story seem plausible. If they are to be proven extrinsically there is both the danger of error in their reproduction by witnesses who heard them and the confusing effect which the extra testimony will have on the jury to outweigh the slight value they will have to the case. For certain types of prior consistent statements, however, it would seem appropriate to extend the principle of hearsay rule partially satisfied by the courtroom conditioning of the witness concerning his prior unconditioned narration.

One of these is the prior identification of an accused person. The hearsay rule is frequently invoked to exclude proof that the prosecuting witness identified the accused person shortly after the crime. Yet, as the prosecuting witness is usually in court and subject to the conditioning devices, this would seem an excellent opportunity to avail of the principle of hearsay

18. Dean Wigmore's suggestion is mentioned and references concerning it are given, supra note 7 . It must be taken that he means to contend for narrative effect for such statements, because he emphasizes the fact of the narrator being subjected to cross-examination, a matter of moment only when the statements are used in a narrative way. And yet Dean Wigmore lists all inconsistent statements of witnesses as circumstantial utterances. Apparently he considers those admitted by the witness to be also entitled to such weight as they may have as narrative. 
rule partially satisfied by courtroom conditioning as to prior narraticn. This is particularly so when we remember that the dramatic nature of a policestation identification is such that there is little danger of error in its being reproduced in court. Errors in perception, recollection, and narration are likely to be at a minimum concerning the fact of identification.

The other example of the prior consistent statement is that of recent complaint in rape which does, when shorn of its content, get around the hearsay rule as conduct. But why should it not, with its content, also be admissible as hearsay rule partially satisfied if the prosecutrix is subject to the conditioning devices at the trial ? $^{19}$ As for former identification, there is little likelihood of error in the reproduction of her former statement because of the dramatic nature of its utterance and the simplicity of its content.

A matter which involves both the use of prior oral statements to refresh recollection and the principle for the use of former testimony as such is found in the case of Stearns Lumber Co. v. Howlett. ${ }^{20}$ In that case a witness who had testified at the first trial was also called as a witness at the second trial. Meanwhile he had completely forgotten the things as to which he had testified at the first trial. There was available the stenographer from the first trial and the stenographic transcript of the testimony. This transcript could not be used as a record of the past recollection of the witness because it was not made by him, nor under his direction, nor verified by him. It did not "refresh" his recollection at all. It could not be used to impeach him because it was not inconsistent with anything testified to by him at the second trial. It could not be used under the principle for former testimony because he was neither dead nor otherwise unavailable as a witness. And yet it would have been as trustworthy as any testimony normally usable under the principles just mentioned. It would seem to be a most excellent example of a prior oral "record of past recollection" with no danger of error in reproduction, inasmuch as it could be reproduced by a trained stenographer with the aid of his written record of his past recollection of what the witness formerly said. Better yet, the principle for former testimony should be extended to situations where the memory of the witness dies as well as to those where he himself dies or disappears. That testimony of such trustworthiness can be excluded by the present rules shows that the principle of hearsay rule partially satisfied can well be extended to cover other situations where the witness can presently be conditioned concerning narration previously made without conditioning. ${ }^{21}$

19. See also WIGMORE, op. cit. supra note 3 , $\$$ I760, concerning the desirability of a genuine exception to the hearsay rule for the contents of complaints of rape. This would be an extension of the existing exception for spontaneous exclamations.

20. 239 Mass. 59, I3I N. E. 217 (I921).

2I. Perhaps the doctrine of hearsay rule partially satisfied by the ex post facto conditioning of the narrator in the courtroom might provide the most plausible narrative theory of admissions. This would be that admissions are narrative, which is trustworthy because the 


\section{General considerations}

It is fashionable to explain the whole hearsay rule in terms of the requirement of cross-examination, i. e., to hold that the rule excludes testimony which has not been cross-examined. ${ }^{22}$ But this view seems improperly to ignore the other conditioning devices which, in co-operation with crossexamination, seek to improve the trustworthiness of normally unreliable human narration in order to make it worthy of being considered by a jury without the danger of their deception. The present writer prefers the view that it is the absence of all the conditioning devices and the benefits of normal testimonial narration which makes hearsay objectionable, and not merely the absence of cross-examination.

To be sure, cross-examination is the most effectual of the conditioning devices which exist for improving the trustworthiness of testimony. While it shares with the other devices the task of avoiding consciously false testimony, its greatest influence lies in showing up testimony which is untrustworthy because of defects in perception, recollection, and narration. Not only does it apply the stimulus of fear of self-contradiction to the narration but it aids the cause of trustworthiness by drawing out more details of the witness' knowledge and by demonstrating shortcomings in his processes of perception, recollection, and narration, as well as by bringing out other personal factors which throw suspicion on his testimony. Then, too, whenever there is cross-examination in the normal manner, the testimony is given ander the possible presence of all the other conditioning devices. They are actually achieved along with cross-examination. Perhaps "cross-examination" means "cross-examination and all the rest of the conditioning devices". But why not say so in explaining the hearsay rule?

The writer feels that it fits the hearsay rule better into its niche in the general analysis of the law of evidence to explain hearsay as human testimony in the raw, unfit to be used for narrative purposes unless it has been exposed to all the processes set up for all raw human testimony and without which none may be considered. To emphasize only one of these processes is to slight the others. A better understanding of them all will be achieved if all are considered in connection with a rule which, when analyzed, is seen to be nothing more than a detailed application of the several requirements for the improvement of all human testimony. Thus it is that the writer feels

party-narrator can put himself on the witness stand and be subjected to the conditioning devices at the time the case is heard. This would fail, however, as explanatory of vicarious admissions for which, as the rules apply, there is no requirement that the speaker be available for a subsequent exposure to the conditioning devices. And even for express admissions there is no actual requirement that the party-speaker be subjected to, or even be available for subjection to the conditioning devices. Dean Wigmore suggested this when he adhered to the hearsay rule waived theory; WIGMORE, op cit. supra note 3, § I048. But see Professor Gifford's demolition of it, discussed in note 43 infra, to appear in the concluding installment of this article in the April issue of the Revinw.

22. See, among others thus emphasizing cross-examination, Morgan, supra note 4, III, at 712 ; Morgan, supra note $4, \mathrm{~V}$, at I 138; and WIGMORE, op. cit. supra note 3 , $\$ \$ 1362,1367$. 
that the topic of former testimony and past recollection recorded should be named "hearsay rule partially satisfied" by the incomplete or imperfect application of all the conditioning devices, rather than that the former topic should be styled "hearsay rule satisfied" by the application of cross-examination.

An example of the analytical error into which the theory that crossexamination alone explains the hearsay rule can lead is seen in the view of Professor Morgan concerning the genuine hearsay exceptions. ${ }^{23} \mathrm{His}$ view is that the absence of cross-examination is the explanation of the hearsay rule. He further rejects the view that there is a positive stimulus to trustworthiness in the case of the hearsay exceptions. On this latter point the present writer is in accord. But Professor Morgan goes farther than a mere theory of the intrinsic superiority of the narration in the genuine hearsay exceptions and holds that the circumstances thereof are such as to accomplish the same thing as cross-examination does when it is actually applied, i. e., to afford to the fact finder a sufficient basis for evaluating the probable trustworthiness of the utterance, particularly with respect to the accuracy of the perception, recollection, and narration of the individual witness in the given instance. With this the present writer disagrees inasmuch as he feels that in the cases of the genuine hearsay exceptions there is not given to the jury any opportunity to "evaluate" the probable trustworthiness of the particular utterance as is the case when cross-examination is actually applied, but that the rationale is that the types of utterances are probably so trustworthy that they may be considered by the jury on faith without the need for evaluating them, either by cross-examination alone, or with the aid of all the conditioning devices.

When the witness is actually cross-examined in the presence of the fact finder, or when the narration was previously so conditioned at the time thereof, or the witness is presently cross-examined with respect to the former narration, then the jury does have an opportunity to make a positive judgment of the probable trustworthiness of the narration. But how can they judge of the likelihood of accurate perception, recollection, and narration when all they have is the reproduced statement of the now absent witness? Is it not more accurate to say that in the cases of the genuine hearsay exceptions the law has already evaluated the utterance for the jury on a basis of normal similar utterances and, having weighed this one in the light of the normal ones, permits it to be considered by them without further evaluation? It seems hard to conceive of a jury's "evaluating" each separate utterance reproduced for them by some one who heard it when uttered. It is easier to think of them as evaluating an utterance when the actual cross-examination of the very narrator directs their attention to the details of the given utterance or related group thereof as such. In such a spirit the writer plans now

23. Supra note 4, III, at 7I2, 7I4-7I7. 
to approach the problem of the genuine hearsay exceptions believing, as he does, that their rationale is the intrinsic superiority of the narration, which justifies its being considered without conditioning and without evaluation.

\section{The Genuine Hearsay Exceptions}

The other general heading permitting extra-judicial utterances to be used as testimony and for narrative purposes is that of the genuine ${ }^{24}$ hearsay exceptions. Herein it is permitted to offer as testimony extra-judicial utterances which have been made without any of the conditioning devices because for good reasons these are entirely dispensed with.

In the typical situations recognized by the specific separate exceptions certain species of such extra-judicial narration are permitted to be considered by the fact finder because it is believed that, first, expediency demands the running of the risk incidental to dispensing with the normal conditioning devices and, second, the particular types of narration thus permitted are less than normally likely to be so untrustworthy that the conditioning devices are necessary to avoid jury deception. These two factors are customarily called the "necessity" and the "circumstantial guarantee of trustworthiness." The typical hearsay exceptions recognized in the law are those which became established when the law of evidence was crystallizing. There is no general exception to the hearsay rule for all extra-judicial narration for which there is a "necessity" and a "circumstantial guarantee". Rather there are specific exceptions each applicable to a typical narrow situation, for each of which there are both a specific necessity and a specific circumstantial guarantee. Certain type situations have by historical accident been recognized to the exclusion of others which, no doubt, possess just as compelling qualities along these lines.

The "necessity" varies for the different exceptions, which fall into three groups separable according to the differences therein. ${ }^{25}$ One group (statements of physical and mental condition and spontaneous exclamations) is based on the theory that it will be impossible to secure as good testimony as the hearsay itself even though the declarant be called to the stand as a witness in the ordinary manner, because of the superiority of contemporaneous narration. Another group (government records and business records) permits extra-judicial narration because of the inconvenience of locating or producing the original declarant himself even though he might actually be available as a witness. The third group (dying declarations, declarations against

24. By "genuine hearsay exception" is meant a principle permitting the use as narrative of utterances to which none of the conditioning devices is ever applied. Such exceptions must be distinguished from those apparent exceptions to the rule which permit utterances to be used for other than narrative effect, or if for narrative effect, because the conditioning devices, or some of them, are eventually applied to the narrator. "Exception" is sometimes used loosely to cover these latter propositions.

25. See WIGMORE, op. cit. supra note 3, \$§ I42I, I425. 
interest, and, as well, almost all of the miscellaneous exceptions) is based upon the necessity indicated by the death or other unavailability of the declarant as a witness which would cause a total loss of his relevant knowledge were it not permitted to use his extra-judicial "testimony".

The "necessity" element of the hearsay exceptions has little psychological implication. It is more a matter of weighing the considerations of expediency which are involved in the three recognized types. The "circumstantial guarantee" element of the hearsay exceptions does, however, have its psychological implications. These psychological considerations have greater or smaller emphasis as one conceives the import of "circumstantial guarantee". If one thinks of it as meaning a positive stimulus to trustworthiness equal in efficacy to the normal conditioning devices, then psychological problems of the first order raise their heads. If , on the other hand, one feels that the true rationale of the hearsay exceptions is not the presence of a positive stimulus equal to the conditioning devices, but rather the absence of the normal likelihood of untrustworthiness in human narration which makes these devices necessary, the psychological implications are of a slighter nature. The present writer prefers the latter viewpoint and feels that there should be substituted for the phrase "circumstantial guarantee" that of "intrinsic superiority" as referring to the quality for trustworthiness of the narration permitted by the genuine hearsay exceptions. He feels that the real psychological problem of the hearsay exceptions should be stated as: "Is the testimony permitted by a given exception likely to be so unusually free from the normal defects of human perception, recollection, and narration as to make the conditioning devices supposed to compensate for those defects exceptionally unnecessary?" rather than as: "Is it psychologically valid to assume that certain external stimuli present at the time of the utterance are equal in effect to the conditioning devices?"

Analysis discloses that all the hearsay exceptions apparently possess unusually favorable conditions for perception, recollection, and narration, and involve the absence of motivation calculated to lead to falsehood. If this be so, it would seem that the circumstantial guarantee conceived as a positive stimulus would be an afterthought. It is planned in treating the specific hearsay exceptions in turn to go thoroughly into the circumstantial guarantee of each in order to see whether there can be discerned a positive stimulus to trustworthiness functioning as the equal of the conditioning devices or whether the matter really is one of the negative intrinsic superiority of the utterance, i. e., its freedom from the normal defects which make the devices necessary. ${ }^{26}$ The writer feels that not only does the "intrinsic superiority" approach better explain the existing exceptions, but that ap-

26. See Morgan, sitpra note 4, III, at 7I2, 7I4-7I7, surveying all the departures from the hearsay rule in terms of their intrinsic superiority. 
proaching the whole group of exceptions in such a vein lays a better foundation for statutory reform and extension of the hearsay exception doctrine.

The theory of intrinsic superiority as the explanatory factor for the trustworthiness of the hearsay exceptions is based on an idea that in their case there is absent the normal danger of faulty perception of the fact in question, poor recollection, erroneous phrasing of narration, and motive to lie. All these are the defects of normal human testimony which make mandatory the conditioning devices calculated to avoid them. Thus it is that an analysis of the hearsay exceptions in turn will call for examination of each of them from these four angles: (I) Perception-how likely was it that the subject matter of the narration was itself capable of being observed without mistake, or that unusual factors focused the attention of the declarant upon it? (2) Recollection-was the interval between perception and narration so brief that loss of meaning due to forgetting was unlikely, or if not, was the fact to be remembered so vividly perceived, or so unusual, as to make it unlikely that the normal loss of memory would occur? (3) Narration-was the fact one capable of simple narration in unmistakable terminology? (4) Motivation to falsify-was there anything about the circumstances of the narration making it abnormally unlikely that the speaker would lie about the subject?

A matter common to all the genuine hearsay exceptions is the application to them of all the evidential requirements which would be applicable to the narration of the same facts by the speaker were he present and on the witness stand. This naturally follows from the concept of the hearsay exceptions permitting the use of statements as testimony. As seen from the preceding discussion, a first and obvious example of this is the requirement that the utterance apparently be the perceived and recollected knowledge of the declarant. The elements of testimonial evidence must be observed. The conditioning devices, as already indicated, are dispensed with. The rule against leading questions is hardly a factor to be reckoned with, first, because so few admissible hearsay statements are made in response to questioning and, second, because the rule would probably not apply anyhow inasmuch as there is usually no question of the declarant being a "friendly" or a "hostile" witness under the rule. ${ }^{27}$ The opinion rule is frequently raised as an objection to dying declarations and, to the extent to which it may be raised, is a problem for all hearsay exceptions save that in those based on "reputation" there is accepted much that contains both the opinion of various extra-judicial speakers and their reflection of further hearsay told them. The hearsay rule itself applies as an aspect of the requirement of testimonial knowledge save

27. Save that an accusatory dying declaration would be of such a nature as to make the narrator a witness "for the State". Compare the rule applicable to some of the genuine hearsay exceptions that the statement to be admissible must have been made ante litem motam. That the statement is post litem motam makes it likely that the narrator is consciously testifying for one side of the case only. 
that the rules for government and business records, as well as those just mentioned, on occasion accept hearsay on hearsay. Rules excluding witnesses because of their personality may also serve to exclude their otherwise admissible hearsay statements. But such rules are today few in number. The exclusion of atheists is frequently raised in connection with dying declarations. The whole calendar of rules of confusion and of extrinsic policy would as well apply to testimony brought into court by way of a genuine hearsay exception as to that brought in by normal testimony and would exclude it if it tended to confuse the jury or to violate some recognized extrinsic policy.

\section{Statements of physical and mental condition}

Based on a "necessity" indicated by the superiority of contemporaneous narration over subsequent narration in the courtroom there is the genuine hearsay exception for statements by one concerning his then existing physical or mental condition. One's statements of his contemporaneous physical condition, if made spontaneously, may be offered as narrative, as may one's statements narrating ${ }^{28}$ a then present mental condition of intention, belief, motive, or emotion. No possible positive stimulus to trustworthiness by way of a circumstantial guarantee is presented for this exception. Rather the only justification is the intrinsic superiority of the utterance. One's contemporaneous physical or mental condition is a fact likely to be accurately perceived, in need of being remembered for but the briefest of intervals, capable of narration in simple and unmistakable terms, and normally lacking any apparent motive for falsehood. The simplicity of the utterance makes for accurate reproduction. More so perhaps than for any of the other genuine hearsay exceptions does this type of narration possess intrinsic superiority making unnecessary any conditioning or evaluation of the utterance with respect to its trustworthiness.

\section{Spontaneous exclamations}

A statement concerning a startling event, made by a person while still under the influence of the event is admissible to prove the truth of its content. The "necessity" is the same as for the previously discussed exception. The positive circumstantial guarantee is sometimes thought to be found in the excited state of mind produced by the event. Hutchins and Slesinger ${ }^{29}$ have purported to destroy the psychological validity of the exception by pointing out the relative untrustworthiness of narration made under mental stress. But does this do any more than to destroy the theory of a positive

28. Distinguish narrative statements showing intent from circumstantial ones having the same effect. The former come in under the genuine exception now being discussed, the latter as circumstantial utterances under that heading of hearsay rule inapplicable.

29. Hutchins and Slesinger, Some Observations on the Law of Evidence-Spontaneous Exclainations (1928) 28 CoL. L. REv. 432. 
stimulus to trustworthiness? There is still left the theory of the intrinsic superiority of the narration made under these circumstances to justify dispensing with the conditioning devices.

In the situations permitted by the exception there is superiority in the elements of perception, recollection, and narration, and, because of the startling event, absence of possibility of motive to falsify. That the witness was startled by the event indicates that he must have been attending the fact of the event, i. e., the subject matter of his perception. The startling nature of it creates that "intent to remember" which, psychologically speaking, improves recollection. The requirement that the narration be made before the effect of the event wears off indicates that the interval between perception and narration is of the briefest. Then there are avoided dangers of faulty recollection. The danger of error in choice of words for narration is probably a normal one in such a case, but the usual events producing spontaneous exclamations are of such a nature that there is little likelihood of the choice of the wrong words for description. The same factors make for less than normal chance of error in reproducing the fact of the utterance in the courtroom. The witness who heard the spontaneous exclamation probably attended well to the fact of its utterance in view of the startling event happening at the time. It is also probable that his recollection was better than usual because of the vivid nature of the fact. As his narration consists of the quotation of a small group of words there is little chance of his making an inept choice of phraseology.

May it not be said that we can ignore the "startling event" as a positive stimulus to trustworthiness and rather can rationalize it as a rule of thumb which does delimit situations wherein superior attention to the fact (perception), brevity of the interval of recollection, an intent to remember, simplicity of narration, and absence of motive to falsify all concur? Does not this indicate an intrinsic superiority of that which is permitted? As a result the conditioning devices are exceptionally unnecessary.

\section{Government and business records}

It is planned to discuss as one the two separate hearsay exceptions for government and business records. While their historical development has been dissimilar and, for that matter, each one represents the convergence of separate subsidiary principles, yet their theory is the same, as the rules are today conceived. Properly kept government records and properly kept business records are admissible in evidence as narration, i. e., to prove the truth of the entries to be found in their content. And this is so today, in either event, regardless of whether the entrant of the particular entry himself had personal knowledge of the fact he was entering. Both for government and for business records it is now recognized that it is safe to trust hearsay 
upon hearsay, i. e., to take government records which are copies of other government records which may in turn be copies of still other original documents and to take business records based on less formal records prepared by the person who actually had the personal knowledge of the transaction. So intrinsically superior is this type of narration that hearsay upon hearsay may be permitted without fear of jury deception.

The "necessity" is of the second type, i. e., the inconvenience of producing the original declarant who possesses the actual knowledge of the fact. This, long the rule for government records, recognizes that it would unduly disrupt the business of government offices to have their officials forever appearing in court to testify as to their acts, and so it is that their certificates thereof have been accepted instead. Only more recently ${ }^{30}$ has the parallel rule for business records dispensed with the need for accounting for the original entrant so that today the necessity is the same for them, i. e., the inconvenience of disrupting the bookkeeping offices of modern business houses to bring their employees to court.

The circumstantial guarantee is the same for both exceptions. For each there is a vestige of positive stimulus to trustworthiness. Each also has obvious intrinsic superiority. The former is vaguely present in the so-called "duty" to the public or to the employer and in the fear of discharge or of censure when inaccurate entries are discovered. This is thought to provide a positive stimulus to the making of the narration at the time it is made. But the prime justification for the trustworthiness of the government and business records is the intrinsic superiority of the type of narration.

The content of government and business records is narration of the highest possible sort. Perception is not a problem at all. It may be of an event being conducted in the presence of the entrant and in which he participates (sale of goods, issuance of license, birth, or death, for examples) so that it is highly likely that he gives the event unusual attention. Or it may involve his copying (and usually comparing) an already prepared writing to which his attention is directly addressed. Recollection is not a problem, as it is customary to make the entry promptly after the event, or immediately after looking at the writing which is being copied. Narration is likely to be unusually accurate inasmuch as it is expressed in stock phrases (dollars and cents, routine business and government events) or because comparison is made between the writing to be copied and the copy made by the entrant. Underlying all three stages of the testimonial process is the idea that the perception, recollection, and narration are being made by

30. Recent cases have taken the advanced step of permitting the use of business records without either producing the entrant of the particular record or showing his unavailability. The Model Statute for proof of business transactions, drafted by the Commonwealth Fund Research Committee, takes the same step. See Morgan et al., The Law of Evidence: SoMe Proposals FOR ITS Reform (Ig27) 5I, 63. 
persons trained in the particular art, whose usual work is the making of accurate perception, recollection, and narration of the facts of government and business activity. The inertia of their jobs makes for accuracy. Motivation to falsify is precluded by the duty, the likelihood of discharge and censure for false entries, the likelihood of inaccurate entries being discovered (public inspection of government records, dissatisfied customers in business), and the rush of the work.

The two separate exceptions differ primarily in the typical form of proof of the fact of the original entries which may be used. In either event, of course, the mode of reproduction in court is of a highly superior type, i. e., real evidence or an examined copy. But for government records, under appropriate statutes, it is customary to permit proof by properly certified copy. Business records, on the other hand, are rarely permitted to be proven by certification and must be evidenced in court by some witness who knows of the manner in which the records are kept and that the specimen produced is from such a set of records. The Model Statute ${ }^{31}$ for business records goes far toward simplifying and reforming the anciently confused law for business records. Would it not be well to have a similar statute for government records to work out a unitary rule for certified copies from all government agencies in place of the present sporadic statutes authorizing certificates from various agencies, one statute for each? For that matter, why not have a single statute for both government and business records, providing for certified copies from the former agencies and for the attestation of the latter before a proper government official? Is not an original government record really one kept in the regular course of a business?

One limitation seems appropriate even under a reformed rule for both government and business records. That concerns the extent to which the entry should be of a matter within the personal knowledge of the entrant. While the rule for government records has always recognized entries not necessarily within the personal knowledge of the entrant, the rule for business records has only recently reached the same stage. While it is too awkward to require that the very entrant of the entry produced in court should have personal knowledge, since to do so would render it too difficult to prove composite records, still it is sound to restrict the rules for government and business records to entries ultimately based on the personal knowledge of someone in the record-keeping system or whose function it is regularly to make entries. The writer feels that the case of Johnston $v$. Lutz, ${ }^{32}$ which

3I. See supra note 30 for a reference to the Model Statute.

32. 235 N. Y. I24, 170 N. E. 517 (I930). The Court affirmed the exclusion from evidence of a policeman's report of the accident, filed at the station house in routine fashion, which contained the policeman's memorandum of the statements of bystanders who (unlike himself) had actually seen the accident. Said the Court: "It was not intended (by the Model Statute) to permit the receipt in evidence of entries based upon voluntary hearsay statements made by third parties not engaged in the business or under any duty in relation thereto. . . ." 
at first seems restrictively to interpret the broad terminology of the Model Statute, is in substance a sound one. To permit the rule for business records to render admissible regularly kept statements of hearsay reported by strangers to the system would, so it seems, violate the principle of intrinsic superiority. The writer feels that the rules for government and business records should go no farther than to admit regular entries of facts either known by the entrant, or based on remoter regular entries ultimately going back to one by some participating member of the record system (sales person, reporting doctor, undertaker) who does have the actual personal knowledge of the fact reported. This limitation would avoid the normal danger of untrustworthiness in the perception, recollection, and narration of people who are not regular participants in the system of keeping records, who are not trained in the art, who have no duty or fear of censure, and for whom the facts narrated are of the ordinary sort and are susceptible to all the dangers of error in the three stages of the testimonial process.

[To be concluded]

This statement shows the philosophy of the case and one might query the validity of another statement: "The memorandum in question was not made in the course of any business, profession, occupation, calling" in view of the words of the statute: “. . . shall include business, profession, occupation and calling of every kind". (Italics added.) Then, too, what of the phrase of the statute: ". . . lack of personal knowledge by the entrant or maker, may be shown to affect its weight, but they shall not affect its admissibility." (Italics added.) 